UTILITY: Jurnal IImiah Pendidikan dan Ekonomi

Volume 4, No. 2, Agustus 2020: Page 10-16

ISSN 2549-1377 (Print) || ISSN 2549-1385 (Online)

Available online at http://journal.stkipnurulhuda.ac.id/index.php/utility

\title{
PENGARUH METODE JIGSAW TERHADAP HASIL BELAJAR PESERTA DIDIK PADA MATA PELAJARAN IPS KELAS VII MTS NURUL HUDA SUKARAJA
}

\author{
Gustina Masitoh $^{1}$, Rusmiati ${ }^{2}$, Rafika Rahmadani ${ }^{3}$ \\ 1,2,3 Prodi Pendidikan Ekonomi STKIP Nurul Huda Sukaraja \\ *Email: gustinamasitoh9@gmail.com
}

\begin{abstract}
Abstrak:Penelitian ini bertujuan untuk mengetahui Pengaruh Metode Jigsaw terhadap Hasil Belajar Peserta Didik Mata Pelajaran IPS Kelas VII MTs Nurul Huda. Penelitian ini menggunakan Metode Eksperimen dalam bentuk quasi eksperimen dengan jenis Nonequivalent Control Group Design. Sampel penelitian ini adalah simple random sampling. Pengolahan data menggunakan analisis deskriptif untuk mengetahui gambaran data yang diperoleh serta analisis inferensial dengan uji-t. Analisis data menggunakan uji normalitas dan uji homogenitas. Hasil penelitian menunjukan bahwa terdapat perbedaan antara kelompok siswa dengan Metode Jigsaw dan kelompok siswa dengan model pembelajaran konvensional. Nilai rata-rata hasil belajar yang dicapai oleh kelompok siswa dengan Metode Jigsaw lebih baik dibandingkan dengan kelompok siswa dengan model pembelajaran konvensional. Hasil hitungan dari 28 peserta didik kelas eksperimen dan 29 peserta didik kelas kontrol diperoleh bahwa $\mathrm{t}_{\text {hitung }}(5.774)>\mathrm{t}_{\text {tabel }}$ (1.673). Jadi terdapat pengaruh Metode Jigsaw terhadap hasil belajar peserta didik pada mata pelajaran IPS kelas VII MTs Nurul Huda Sukaraja.
\end{abstract}

Kata Kunci: Metode Jigsaw dan Hasil Belajar.

\section{PENDAHULUAN}

Pendidikan merupakan kegiatan mengembangkan potensi dan keahlian yang dimiliki individu sebagai bekal untuk mensejahterakan kehidupan, hal yang utama dalam pendidikan terdapat dalam proses belajar dan pembelajaran (Darmadi: 2019). Pada proses pendidikan terdapat suasana pengajaran yang dilakukan oleh pendidik dan peserta didik. Suyono (2013: 9) mengatakan bahwa "belajar adalah suatu aktivitas atau suatu proses untuk memperoleh pengetahuan, meningkatkan keterampilan, memperbaiki prilaku, sikap dan mengokohkan kepribadian". Salah satu faktor yang menentukan kualitas pembelajaran adalah metode pembelajaran.

Model pembelajaran disusun berdasarkan berbagai prinsip-prinsip pembelajaran, teori-teori psikologis, sosiologis, analisis sistem atau teori-teori lain yang mendukung (Trisianawati: 2015). Rusman (2013) menyatakan bahwa model pembelajaran kooperatif adalah bentuk kegiatan pembelajaran dengan cara siswa belajar dan bekerja dalam kelompok kecil secara kolaboratif yang terdiri dari empat sampai enam orang dengan struktur kelompok yang heterogen. Menurut Fathoni (2015: 11) Metode Jigsaw merupakan model belajar kooperatif dengan cara siswa 


\section{Pengaruh Metode Jigsaw Terhadap Hasil Belajar Peserta Didik Pada Mata Pelajaran Ips Kelas VII Mts Nurul Huda Sukaraja}

belajar dalam kelompok kecil yang terdiri dari empat sampai enam orang secara heterogen (beragam) dan siswa bekerja sama saling ketergantungan positif dan bertanggung jawab secara mandiri.

Berdasarkan pengamatan/observasi dilapangan pada PPL kependidikan II selama tiga bulan pada tanggal 10 September s.d 10 November 2018 di sekolah MTs Nurul Huda Sukaraja. MTs Nurul Huda merupakan salah satu lembaga pendidikan formal yang menyatu langsung dengan pondok pesanten Nurul Huda Sukaraja. Penelitian ini mengambil kelas VII-1 yang berjumlah 28 siswa, hanya terdapat 13 peserta didik yang dapat mencapai kriteria ketuntasan minimal dengan memperoleh nilai $>70$, sedangkan 15 peserta didik lainnya belum dapat mencapai kriteria kentuntasan minimal dengan memperoleh nilai $<70$. Hal ini disebabkan oleh beberapa faktor diantaranya siswa pasif dalam proses belajar pembelajaran, karena, guru tidak menggunakan metode yang bervariasi dalam proses pembelajaran sehingga siswa merasa bosan, didalam kelas tidur dan selalu mengabaikan pembelajaran. Oleh karena itu, agar kegiatan dan proses pembelajaran mata pelajaran IPS dapat diminati peserta didik dan terkesan menyenangkan. Maka perlu adanya penggunaan metode pembelajaran yaitu Metode Jigsaw dalam proses pembelajaran agar peserta didik lebih giat untuk belajar dan lebih semangat untuk mengikuti kegiatan belajar dikelas dengan baik.

Dengan latar belakang di atas, peneliti mencoba untuk menciptakan hal yang baru, maka penulis menggunakan judul "Pengaruh Metode Jigsaw Terhadap Hasil Belajar Peserta Didik Pada Mata Pelajaran IPS Kelas VII MTs Nurul Huda Sukaraja". Berdasarkan latar belakang di atas, maka rumusan masalah penelitian adalah "Apakah Terdapat Pengaruh Metode Jigsaw Terhadap Hasil Belajar Peserta Didik Pada Mata Pelajaran IPS Kelas VII MTs Nurul Huda Sukaraja". Tujuan yang diharapkan dari dilaksanakan penelitian ini adalah untuk mengetahui Pengaruh Metode Jigsaw Terhadap Hasil Belajar Peserta Didik Pada Mata Pelajaran IPS Kelas VII MTs Nurul Huda Sukaraja.

\section{METODE}

Metode yang digunakan Peneliti adalah metode kuantitatif dengan desain Quasi Experiment dalam bentuk Non-equivalent control grup design (Sugiyono:2013). Populasi dalam penelitian ini seluruh kelas VII di MTs Nurul Huda Sukaraja, terdapat kelas VII-1 berjumlah 28 siswa, VII-2 berjumlah 34 siswa, VII-3 berjumlah 32 siswa dan kelas VII-4 berjumlah 29 siswa. Pengambilan sampel adalah simple random sampling yang ditunjukan pada kelas VII-1 sebagai kelas eksperimen dan VII-4 sebagai kelas kontrol. Ada dua teknik pengumpulan data dalam penelitian ini adalah (1) Angket dalam pegukurannya menggunakan angket skala likert dan (2) Tes yang ditunjukan beupa pretest dan posttest. Teknik analisis data menggunakan rata-rata (mean), standar deviasi dan kategori tinggi, sedang, rendah. Uji prasyarat data adalah normalitas dan homegenitas. Analisa data yang digunakan adalah analisa uji 
t-test.

\section{HASIL DAN PEMBAHASAN}

\section{HASIL}

Hasil Perbedaan nilai rata-rata metode Jigsaw dan hasil belajar kelompok eksperimen dan kelompok kontrol sebelum dan sesudah intervensi

\begin{tabular}{|c|c|c|c|c|}
\hline \multicolumn{4}{|c|}{ TES (Hasil Belajar) } & \multirow{2}{*}{$\begin{array}{l}\text { Angket } \\
\text { (Metode } \\
\text { Jigsaw) } \\
\text { Kelompok } \\
\text { eksperimen }\end{array}$} \\
\hline & & Eksperimen & Kontrol & \\
\hline \multirow[t]{2}{*}{ Mean } & Pretest & 62.14 & 59.83 & \multirow[t]{2}{*}{83.95} \\
\hline & Posttest & 81.07 & 65.52 & \\
\hline \multirow[t]{2}{*}{ SD } & Pretest & 10.923 & 59.83 & \multirow[t]{2}{*}{7.968} \\
\hline & Posttest & 8.857 & 65.52 & \\
\hline \multirow[t]{2}{*}{$\begin{array}{l}\text { 1. Maksimum } \\
\text { 2. Minimum }\end{array}$} & Pretest & $\begin{array}{ll}\text { 1. } & 85 \\
\text { 2. } & 45\end{array}$ & $\begin{array}{ll}1 . & 80 \\
\text { 2. } & 40\end{array}$ & \multirow{2}{*}{ Max (95) } \\
\hline & Posttest & $\begin{array}{cc}\text { 1. } & 100 \\
\text { 2. } & 65\end{array}$ & $\begin{array}{ll}\text { 1. } & 90 \\
\text { 2. } & 45\end{array}$ & \\
\hline \multirow[t]{2}{*}{ Kategori } & Pretest & Sedang & Sedang & \multirow[b]{2}{*}{ Sedang } \\
\hline & Posttest & Sedang & Sedang & \\
\hline
\end{tabular}

Berdasarkan hasil penelitian dapat dipaparkan hasil normalitas data adalah Nilai Sig. data posttest untuk kelas eksperimen sebesar $0.200>0.05$, sedangkan posttest kelas kontrol $0.173>0.05$. hasil homogenitas data nilai Sig. $0.161>0.05$. dn uji independen t-test data yang diperoleh nilai Sig.(2 tailed) sebesar 0.000 lebih rendah dari taraf signifikan rata-rata $5 \%(0.05)$. Selanjutnya nilai $t_{\text {hitung }}$ yang diperoleh 5.774 lebih tinggi dari $t_{\text {tabel }}$ 1.673. sedangkan, Kriteria pengujian adalah Ho diterima dan Ha ditolak, jika $t_{\text {hitung }}<t_{\text {tabel }}$ Sedangkan Ho ditolak dan Ha diterima jika $t_{\text {hitung }}>t_{\text {tabel }}$. Dari kriteria tersebut nilai $t_{\text {hitung }}(5.774)>t_{\text {tabel }}(1.673)$ artinya Ho ditolak dan Ha diterima.

\section{PEMBAHASAN}

1. Tingkat Hasil Angket Metode Jigsaw Pada Mata Pelajaran IPS Kelas VII MTs Nurul Huda Sukaraja

Hasil angket Metode Jigsaw pada mata pelajaran IPS. Diketahui bahwa, mayoritas siswa kelas VII-1 MTs Nurul Huda Sukaraja memilih jawaban angket metode Jigsaw yang disebarkan pada 28 responden menunjukan hasil yaitu: $21.4 \%$ dengan katagori rendah yang berjumlah 6 siswa, 57.1\% dengan katagori sedang yang berjumlah 16 siswa dan $21.4 \%$ dengan katagori tinggi yang berjumlah 6 siswa. Dari jawaban tersebut mengindikasikan bahwa pengaruh 


\section{Pengaruh Metode Jigsaw Terhadap Hasil Belajar Peserta Didik Pada Mata Pelajaran Ips Kelas VII Mts Nurul Huda Sukaraja}

metode Jigsaw terhadap hasil belajar pada kelas VII-1 dapat dikatakan efektif.

\section{Tingkat Hasil Belajar Peserta Didik Sebelum dan Sesudah Menggunakan Metode Jigsaw (Kelompok Eksperimen)}

Hasil belajar mata pelajaran IPS dengan materi kegiatan ekonomi kelas VII MTs Nurul Huda Sukaraja. Terdapat kelas eksperimen yaitu kelas VII-1 jumlah siswa 28 dengan menggunakan Metode Jigsaw. Hasil menunjukan, bahwa kelompok kelas eksperimen hasil Pretest yaitu $28.6 \%$ dengan katagori rendah yang berjumlah 8 siswa, 53.6\% dengan katagori sedang yang berjumlah 15 siswa dan $17.9 \%$ dengan katagori tinggi yang berjumlah 5 siswa. Hasil data pretest yaitu 45 sebagai nilai terendah dan 85 sebagai nilai tertinggi, selanjutnya pada kelas VII-1 memperoleh hasil 53,6\% dengan kategori sedang. Hasil posttest yaitu $17.9 \%$ dengan katagori rendah yang berjumlah 4 siswa, $60.7 \%$ dengan katagori sedang yang berjumlah 18 siswa dan $21.4 \%$ dengan katagori tinggi yang berjumlah 6 siswa. Hasil data posttest yaitu 65 sebagai nilai terendah dan 100 sebagai nilai tertinggi, selanjutnya hasil tes yaitu $60.7 \%$ pada kategori sedang. Berdasarkan hasil pretest dan posttest pada kelas eksperimen (VII-1) menunjukan bahwa selisih hasil tes sebesar $18.93 \%$. hasil tersebut menunjukan bahwa pengaruh Metode Jigsaw dengan materi kegiatan ekonomi masuk dalam kategori Moderat.

\section{Tingkat Hasil Belajar Peserta Didik Sebelum dan Sesudah Menggunakan Metode Konvensional (Kelompok Kontrol)}

Hasil belajar mata pelajaran IPS dengan materi kegiatan ekonomi kelas VII MTs Nurul Huda Sukaraja. Terdapat kelas eksperimen yaitu kelas VII-4 jumlah siswa 29 dengan menggunakan Metode konvensional. Hasil menunjukan, bahwa kelompok kelas kontrol hasil Pretest yaitu $27.6 \%$ dengan katagori rendah yang berjumlah 8 siswa, $44.8 \%$ dengan katagori sedang yang berjumlah 13 siswa dan $27.6 \%$ dengan katagori tinggi yang berjumlah 8 siswa. Hasil data pretest yaitu 40 sebagai nilai terendah dan 80 sebagai nilai tertinggi, selanjutnya pada kelas VII-4 memperoleh hasil $44.8 \%$ dengan kategori sedang. Hasil posttest yaitu $13.8 \%$ dengan katagori rendah yang berjumlah 4 siswa, $72.4 \%$ dengan katagori sedang yang berjumlah 21 siswa dan $13.8 \%$ dengan katagori tinggi yang berjumlah 4 siswa. Hasil data posttest yaitu 45 sebagai nilai terendah dan 90 sebagai nilai tertinggi, selanjutnya pada kelas VII-4 memperoleh hasil $72.4 \%$ dengan kategori sedang. Berdasarkan hasil pretest dan posttest pada kelas kontrol (VII-4) menunjukan bahwa selisih hasil tes sebesar $5.69 \%$. Hasil tersebut menunjukan bahwa hasil tes yang menggunakan metode konvensional dengan materi kegiatan ekonomi masuk dalam kategori moderat. 


\section{Pengaruh Metode Jigsaw Terhadap Hasil Belajar Peserta Didik Pada Mata Pelajaran IPS Kelas VII MTs Nurul Huda Sukaraja}

Uji normalitas yang diguakan pada peneliti ini menggunakan kolmogrov smirnov test pada program SPSS versi 20 , pada tabel 4.10 di atas, terdapat data hasil uji normalitas pada kelas eksperimen dan kelas kontrol dengan Nilai Sig. data posttest untuk kelas eksperimen sebesar $0.200>0.05$, sedangkan posttest kelas kontrol $0.173>0.05$. Hal ini menunjukan bahwa data posttest kelas eksperimen dan kelas kontrol berdistribusi Normal. Kedua uji homegenitas setelah kedua kelompok sampel penelitian dinyatakan berdistribusi normal, selanjutnya dicari nilai homogenitas. Dalam penelitian ini homogenitas dapat menggunakan levene's pada program SPSS versi 20. pada tabel 4.11 di atas, terdapat data hasil uji homogenitas nilai Sig. $0.161>0.05$. Sesuai dengan kriteria bahwa jika nilai Sig. $>0.05$ maka sampel varian berdistribusi homogen.

Setelah diketahui normalitas dan homogenitas, selanjutnya adalah melakukan uji hipotesis, dalam uji hipotesis peneliti menggunakan program SPSS versi 20 dengan pengujian independent sample $t$-test. Pada tabel $4.12 \mathrm{di}$ atas, diperoleh nilai Sig.(2 tailed) sebesar 0.000 lebih rendah dari taraf signifikan rata-rata $5 \%(0.05)$. selanjutnya nilai t yang diperoleh 5.774 lebih tinggi dari $t_{\text {tabel }}$ 1.673. Kriteria pengujian adalah Ho diterima dan Ha ditolak, jika $t_{\text {hitung }}<t_{\text {tabel }}$ sedangkan Ho ditolak dan Ha diterima, jika $t_{\text {hitung }}>t_{\text {tabel }}$. Dari kriteria di atas nilai $\mathrm{t}_{\text {hitung }}(5.774)>\mathrm{t}_{\text {tabel }}($ (1.673) artinya Ho ditolak dan Ha diterima. Jadi, kesimpulannya terdapat pengaruh Metode Jigsaw terhadap hasil belajar peserta didik pada mata pelajaran IPS kelas VII Mts Nurul Huda.

Hasil penelitian menunjukan bahwa Metode Jigsaw merupakan salah satu alternatif metode yang efektif untuk hasil belajar peserta didik. Hal ini selaras dengan penelitian terdahulu "Umi Rosyidah, 2015 dalam penelitiannya tentang pengaruh model pembelajaran kooperatiif tipe jigsaw terhadap hasil belajar matematika kelas VIII SMP Negeri 6 Metro Tahun ajaran2015/2016". Dengan adanya Metode Jigsaw dalam pembelajaran, maka peserta didik dapat memahami materi yang telah dipelajarinya dan dapat mengerjakan tugas-tugas yang diberikan oleh guru, sehingga nilai akhirnya menjadi lebih baik. maka dari itu, tugas seorang guru dapat menggunakan metode pembelajaran yang sesuai materi pelajaran yang akan diajarkan, sehingga dapat membangkitkan semangat belajar peserta didik. Oleh karena itu, Metode Jigsaw sangat tepat untuk salah satu pemilihan dalam penggunaan metode pembelajaran yaitu proses pembelajaran agar peserta didik dapat mencapai hasil belajar yang optimal. 


\section{Pengaruh Metode Jigsaw Terhadap Hasil Belajar Peserta Didik Pada Mata Pelajaran Ips Kelas VII Mts Nurul Huda Sukaraja}

\section{SIMPULAN}

Berdasarkan hasil analisis data sebagaimana yang dideskripsikan di atas, maka dapat ditarik kesimpulan dari penelitian ini sebagai berikut: (1) hasil Angket Metode Jigsaw, diketahui bahwa pengaruh metode Jigsaw terhadap hasil belajar pada kelas VII dapat dikatakan efektif, dengan presentase $57.1 \%$ kategori sedang (Moderat).(2) hasil tes yang diperoleh, terdapat perbedaan selisih hasil belajar menggunakan Metode Jigsaw dan Metode Konvensional. Hasil menunjukan bahwa Metode Jigsaw sebesar $18.93 \%$ dengan katagori sedang dan Metode Konvensional sebesar $5.69 \%$ dengan katagori sedang. Hasil belajar meningkat setelah menggunakan Metode konvensional dengan kategori Sedang (moderat). Namun, peningkatan hasil belajar menggunakan Metode Jigsaw jauh lebih tinggi dari pada Metode Konvensional. (3) hasil analisis nilai Sig.(2 tailed) sebesar 0.000 lebih rendah dari taraf signifikan rata-rata $5 \%(0.05)$. dengan nilai thitung yang diperoleh 5.774 dan nilai $t_{\text {tabel }}$ 1.673. dalam kriteria pengujian adalah Ho diterima dan Ha ditolak, jika $t_{\text {hitung }}<t_{\text {tabel }}$. sedangkan Ho ditolak dan Ha diterima, jika $t_{\text {hitung }}>t_{\text {tabel }}$. Dari kriteria di atas nilai $t_{\text {hitung }}(5.774)>t_{\text {tabel }}$ (1.673) artinya Ho ditolak dan Ha diterima. Jadi, kesimpulannya terdapat pengaruh Metode Jigsaw terhadap hasil belajar peserta didik pada mata pelajaran IPS kelas VII Mts Nurul Huda Sukaraja.

\section{UCAPAN TERIMAKASIH}

Penulis mengucapkan banyak terima kasih kepada semua pihak yang telah membantu dari proses awal penulisan hingga bisa terbitnya tulisan ini. Kepada teman dan sahabat yang selalu memberikan dorongan semangat untuk segera membuat tulisan. Kemudian, khsususnya bagi pengelola jurnal UTILITY yang telah bersedia menerbitkan tulisan ini.

\section{REFERENSI}

DARMADI, D. H., \& PD, M. (2019). Pengantar Pendidikan Era Globalisasi: Konsep Dasar, Teori, Strategi dan Implementasi dalam Pendidikan Globalisasi. An1mage.

Eka Trisianawati, Tono Djudin dan Rendi Setiawan, 2015. Pengaruh Model Pembelajaran Kooperatif Tipe Jigsaw Terhadap Hasil Belajar Siswa Pada Materi Vector kelas X SMA Negeri 1 Sanggau Ledo Tahun ajaran 2015/2016, jurnal.

Fahmi Fathoni, 2015. Pengaruh model kooperatif tipe jigsaw terhadap hasil belajar IPS di Sekolah Dasar Negeri 11 Pontianak Kota Tahun ajaran 2015/2016, jurnal.

Rusman, 2010. Model-Model Pembelajaran, Depok; PT Rajagrafindo Persada. 
Gustina Masitoh ${ }^{1}$, Rusmiati $^{2}$, Rafika Rahmadani ${ }^{3}$

Sugiono, 2013. Metode Penelitian Pendidikan Pendekatan Kuantitatif, Kualitatif, dan $R \& D$, bandung: Alfabeta.

Sugiyono. 2010. Statistika Untuk Penelitian.Bandung : Penerbit Alfabeta.

Suyono \& Hariyanto. (2012). Belajar dan Pembelajaran. Bandung: PT Remaja Rosdakarya Offset 